\title{
A Endocrinologia Feminina ea Mulher na Endocrinologia
}

C OM ESTA EDIÇão ESPECIAL dos "Arquivos" sobre Endocrinologia Feminina, coordenada por Ricardo M eirelles, fechamos um ciclo de temas seletos dedicados a áreas específicas da endocrinologia Endocrinologia Básica (agosto de 2000), Endocrinologia Pediátrica (fevereiro de 2001) e Endocrinologia Feminina (agosto de 2001) -, cujas características próprias fazem uma interface importante com áreas de atuação de outras especialidades médicas, a ginecologia, a pediatria e as áreas básicas propriamente ditas.

Logo de início agradeço ao mui estimado Ricardo, este santista-carioca versátil e apreciador de bons vinhos, e a todos os participantes desta edição pela valiosa colaboração, que culminou com um produto da mesma elevada qualidade que tem caracterizado as Edições Especiais da revista, consolidando esta recente diretriz de nossa política editorial.

U ma edição especial que enfoca exclusivamente a endocrinologia da mulher permite ao editor a liberdade para uma pequena digressão, trazendo à pauta um assunto paralelo mas interessante, a mulher na endocrinologia. Este, portanto, me parece um momento apropriado para fazer algumas considerações e divagações.

A medicina do passado, assim como outras atividades profissionais autônomas, era de atuação tipicamente masculina. Muito como era - e ainda persiste -, a atividade profissional ligada às carreiras militar e política. E nem estou voltando tanto no tempo, quando nossas avós e bisavós - sempre as mulheres - ocupavam-se fundamental e exclusivamente da criação dos filhos e dos - hoje reconheço - extenuantes cuidados do lar, deixando para seus companheiros a agradável (árdua?) tarefa de sair de casa, procurar trabalho (antes muito mais fácil) e trazer dinheiro para o sustento da família (quando sobrava sempre um pouco no final do mês). As poucas exceções (ou extravagâncias) daqueles tempos, mais especificamente no campo da saúde, optavam pela enfermagem, psicologia e, tímida mas pertinentemente, pela pediatria. $\mathrm{N}$ ão conheço uma razão aparente para justificar este comportamento, a não ser questões e hábitos culturais da civilização ocidental, mais especificamente da latino-americana.

D ou um salto no tempo. N este ano de 2001, completo 30 anos de formado na medicina (o tempo voa quando você está se divertindo!) e recordo que minha classe de quase 100 alunos já albergava umas 20 colegas (uma proporção, à época, beirando a aberração!). Eram todas bonitas, charmosas, bem arrumadas e absolutamente namoráveis (homenagem tardia mas sincera), e não - como poder-se-ia supor, feias, desleixadas e/ ou enjeitadas. $\mathrm{H}$ oje, a participação feminina nos cursos de medicina é cada vez maior, tendo algumas especialidades médicas se tornado reduto ou domínio quase que exclusivo de mulheres, como a dermatologia, a pediatria e a tocoginecologia. Continuam belas, sensíveis, inteligentes e sofisticadas (homenagem atual e também sincera). O utras áreas, antes inimagináveis para mulheres, e onde os homens reinavam soberanos, também incorporam cada vez mais colegas mulheres, como a traumatologia, a neurocirurgia e a urologia. editorial

\author{
ClaudioE. Kater
}

Editor-chefe, $A B E \& M$ 
Parece razoável, senão lógico, que áreas de atuação médica que tenham como alvo o público feminino e suas conexões, assumam a preferência de escolha pelas muIheres. Assim, a tocoginecologia, a plástica e mesmo a pediatria jamais causariam - mesmo há algum tempo - , tanta estranheza se fossem exercidas fundamentalmente por elas. M as, traumatologia talvez necessitasse de músculos fortes e urologia então de alguma perversão!

A própria endocrinologia é uma especialidade cujo predomínio de indivíduos afetados balança para 0 lado feminino: doenças de tiróide, adrenal e gonadas são habitualmente mais prevalentes entre as mulheres, assim como obesidade e doenças ósteo-metabólicas. Sem falar nas consequências e interrelações com puberdade, gravidez, puerpério, climatério e menopausa. Entretanto, fortuitamente a sub- ou super-especialidade, "endocrinologia feminina", ao invés de enfocar exclusivamente as entidades nosológicas predominantemente relacionadas às disfunções gonadais e aos distúrbios associados à menopausa (que não deixa de ser uma disfunção gonadal fisiológica), ampliou seu cenário e atua em toda a arena das disfunções glandulares e distúrbios do metabolismo.

0 momento ainda é de calmaria, mas se endocrinologistas senso lato já se incomodam com a invasão de seus pretensamente exclusivos domínios por outros especialistas (ginecologistas endócrinos, pediatras endócrinos, reumatologistas, nefrologistas, e até esteticistas e cosmetologistas), o que dizer num futuro próximo onde distúrbios do metabolismo de cálcio, diabetes e obesidade forem disputados entre nós mesmos endocrinologistas, de acordo com a faixa etária e o gênero?

Antes de voltar à mulher, volto a elas através de um homem. No ano anterior à sua morte, Sigmund Freud, o "pai da psiquiatria moderna", permitiu-se 0 seguinte desabafo:

“M inha grande dúvida, que até agora não fui capaz de superar, não obstante meus trinta anos de mergulho na alma feminina, é o que, verdadeiramente, uma mulher quer?".

I sto para dizer o que segue. Enquanto nos Estados U nidos da América, líder da democracia e expoente do Admirável M undo Novo de H uxley, país-modelo na iniciativa de causas sociais e populares, incluindo a independência feminina, a revolução sexual e as causas minoritárias, a recente ex-presidente da Sociedade Americana de Endocrinologia (Endocrine Sociey), Benita Katzenellenbogen que sucedeu a Larry Jameson, e antes dele a outra presidente, $\mathrm{M}$ aria $\mathrm{N}$ ew, faz louvores às várias conquistas de sua administração, incluindo o realce ao M inority A ffairs Committe (do qual fazem parte - pasmem -, as mulheres), nós aqui abaixo, ainda na tentativa da emergência (e onde os homens foram chamados - ainda são? -, machões latinos, porcos chauvinistas e outros adjetivos ainda menos sensíveis), já demos a volta por cima. Q uerem ver al guns números curiosos da nossa SBEM / FEBRASEM e dos ABE\&M ?

Entre os 4 presidentes atuais das Sociedades Afiliadas (SBEM , SBD , ABESO eSO BEM O M) temosuma (25\%) mulher; entre os 6 presidentes de $D$ epartamentos de Especialidade da SBEM temos duas (33\%) mulheres e das várias $D$ iretorias $N$ acionais da FEBRASEM temos 29 membros, dos quais 12 (41\%) são mulheres.

Em relação aos $A B E \& M$, nosso Conselho Editorial $\mathrm{N}$ acional tem 68 membros, com 25 (37\%) mulheres, enquanto meu seleto e particularmente caro Painel de Revisores/ Pareceristas é composto por 155 conselheiros, 58 dos quais (38\%) são mulheres. Embora numericamente inferiores, são extremamente zelosas, pontuais e perceptivelmente mais rápidas que os homens, tornandoas senão mais, pelo menos tão eficientes quanto eles.

Q uando a estatística fica liberada do "bias" e da subjetividade da escolha e seleção de pessoas (e eu agora, mais consciente, faço um mea culpa por não incluir mais mulheres) e passamos a analisar a participação ativa e randômica, a maior contribuição do sexo feminino fica evidente: analisando as autorias e co-autorias dos artigos publicados na revista apenas no ano de 2001 (volume 45, números 1, 2, 3 e 4, este em suas mãos) - já que não tive tempo para avaliar números anteriores, embora não haja razão para suspeitar que sejam diferentes - das 197 autorias, 106 (54\%) são assinadas por mulheres!!! Em nenhum destes fascículos mencionados as mulheres perderam para os homens, apenas empataram no número 2 .

Adicionalmente, o cadastro de assinantes e de associados da SBEM / FEBRASEM que recebem regularmente nossa revista é composto de 2.282 nomes, sendo $56 \%$ de mulheres, e o da Regional de São Paulo (maior e mais atualizado deles) tem 745 nomes, com $54 \%$ de mulheres.

Confirmo, portanto (agora com números incontestáveis), o que já suspeitava há algum tempo: que a comunidade médico-científica que não apenas subscreve e lê, mas também produz e publica nos "Arquivos" é constituída majoritariamente por muIheres. Nós homens é que somos a minoria. Criamos ou não um "Minority Affairs Committe" nos $A B E \& M$ para proteger os direitos dos minoritários endocrinologistas masculinos?

0 maior contrasenso, entretanto, é o seguinte: sou 0 8․ dos oito editores-chefes que os "Arquivos" já tiveram desde sua criação, todos homens! Será que já não está na hora de uma mulher assumir o bastão?

Aguardo manifestações. Da maioria e da minoria, quem quer que sejam ou se considerem! 